\title{
Effects of the Climate on the Students' Recreational Activities Who Comes from Different Climate Types
}

Tahsin YILMAZ

Rifat OLGUN

Derya ATLI

Akdeniz University, Faculty of Architecture, Department of Landscape Architecture

\begin{abstract}
Turkey has a large surface area with different topographic features. For this reason, there are regionally climate types (mediterranean climate, black sea climate and continental climate) that are affected by the natural structure of the regions. The climatic elements (temperature, precipitation, humidity, wind, etc.) that are manifested by these climate types are the most effective environmental factors on the recreational activities of the individuals living in the region. Therefore, the recreational activities preferred by the individuals differ according to the climatic characteristics of the region where they live in. The university life is an important period in the formation of the personalities of individuals and in the acquisition of habits that will continue for years. The recreational activities preferred in this period have an important effect on many aspects of the life of the students. University students go to cities where have different natural and cultural characteristics from the city they live in to continue their university education and they live there. The recreational activities preferences of university students may differ according to the characteristics of the region. The aim of this study is to examine the effect of climate on recreational activities preferred by university students who come from different regions for get a university education. In this context, the data is gathered by applying the questionnaire on coincidentally selected 174 students who are studying at Akdeniz University. The data was analysed via SPSS statistical analyse package software. During the evaluation of the data were used descriptive statistical methods such as Percentage (\%) and frequency (f). These outcomes demonstrate that the climate factor of the region has an important effect on the recreational activities preferred by university students from regions with different climate types. It has been reached that the recreational activities of students who come from the continental climate and the Black Sea climate types are affected positively in the study area where dominant climate type is Mediterranean climate and that the individuals from this climate type prefer the outdoor recreational activities.
\end{abstract}

Keywords: Effects of the Climate on the Students' Recreational Activities Who Comes from Different Climate Types. 